\title{
REYES CONTRA MONARQUÍAS. LA FORMA HERMENÉUTICO-ANTROPOLÓGICA DE CARMELO LISÓN DE DIALOGAR CON GADAMER
}

Kings vs. Monarchies. Carmelo Lisón's HermeneuticalAnthropological form of Dialogue with Gadamer

Reis contra monarquias. A forma hermenêticoantropológica de diálogo de Carmelo Lisón com Gadamer

\author{
José Luis ANTA FÉLEZ \\ Universidad de Jaén \\ jlanta@ujaen.es
}

Fecha de recepción: 12/01/2021

Fecha de aceptación: 23/02//2021

RESUMEN: A través de un texto de Carmelo Lisón, La imagen del Rey, establecemos cuáles son las claves de su diálogo con Hans-Georg Gadamer. Se genera así una metodología donde ambos autores se complementan para entender el juego, el ritual, la estética, las palabras y las formas de representación de los reyes y de la idea de verdad. Pero en este diálogo ficcionado a tres bandas, entre Gadamer, la corte de los Austrias y el propio Carmelo, se genera un campo abierto de pensamiento sobre los dispositivos que llevan a los reyes a construir una imagen para el gobierno, su desarrollo como sujetos políticos y como seres humanos con pasiones, gustos y subjetividades.

Palabras clave: Hermenéutica; Historia moderna; Antropología política; Rey; Monarquía; Ritual. 
ABSTRACT: Through a text by Carmelo Lisón, La imagen del Rey, we establish which are the keys to his dialogue with Hans-Georg Gadamer, thus generating a methodology where both authors complement each other to understand the game, the ritual, the aesthetics, the words and forms of representation of kings and the idea of truth. But in this fictional three-way dialogue, between Gadamer, the Austrian Court and Carmelo himself, an open field of thought is generated about the devices that lead the kings to build an image for the government, for their development as subjects" politicians and as human beings with passions, tastes and subjectivities.

Key words: Hermeneutics; Modern history; Political anthropology; King; Monarchy; Ritual.

RESUMO: Através de um texto de Carmelo Lisón Tolosana, A Imagem do Rei, estabelecemos quais são as chaves de seu diálogo com Hans-Gerog Gadamer. Gera-se assim uma metodologia onde ambos os autores se complementam para entender o jogo, o ritual, a estética, as palavras e as formas de representação dos reis e da ideia de verdade. Porém, neste diálogo fictício há três lados, entre Gadamer, a corte dos Áustrias e o próprio Carmelo, gerando um campo aberto de pensamento sobre os dispositivos que levam os reis a construir uma imagem para o governo, seu desenvolvimento como sujeitos políticos e como seres humanos com paixões, gostos e subjetividades.

Palavras-chave: Hermenêutica; História Moderna; Antropologia Política; Rei; Monarquia; Ritual.

"Et les hommes se racontent des histoires inédites, qui seront toujours les mêmes».

Marcel Mauss.

\section{LA IMAGEN DEL REY, UN TEXTO}

Aunque conozco a Carmelo Lisón desde los primeros años de la de década de los 80 -me pregunto si no tendría que hablar sólo en pasado-, ya que fue primero mi profesor y luego un gran consejero y confidente: le vi construir algunos de sus libros, experimentar con el lenguaje y escucharle en conferencias, comer con él y acudir a las invitaciones que nos hacía a su casa del Parque de las Avenidas para celebrar su cumpleaños, estar presente en la invitación que año tras año me llegaba de la Casa de Velázquez, frecuenté y conviví con Julia, su mujer, e, incluso, con el paso del tiempo llegué a tenerle como una suerte de amigo; a pesar de todo ello, nunca Carmelo me llegó a considerar de su grupo. O más bien no me propuso dentro del primer círculo, ocupado en cierta medida por Ricardo, Gaspar, Enrique, Luis, José Antonio (Fernández de Rota), la incorporación 
definitiva de José Antonio (González Alcantud), a ratos por Mikel y Eloy, aunque de manera distraída estaban también María Jesús, Josepa, Honorio, algunos de sus compañeros ingleses de toda la vida, no pocos académicos y unos franceses, sobre todo, Bernard, e italianos que actuaban ad-hoc. No se crean que había mucho más. Carmelo era un hombre que no desdeñaba el halago y la invitación, siempre con sus condiciones, primero que no estorbaran sus cursos de doctorado y más tarde sus días en la Academia, pero de la misma manera tenía claro quién era ese círculo de protección al que le daba constantes muestras de respeto y cariño. En mi caso estuve siempre cerca, pero nunca dentro.

Si cuento esto es también para que entendamos que el magisterio y las formas de investigar de Carmelo tenían un momento académico, pero también de confianza personal. En este sentido yo me quiero alejar, hasta donde pueda y siempre de manera metafórica, de su obra gallega para centrarme en un libro, La imagen del Rey, Monarquía, realeza y poder ritual en la Casa de los Austrias (Lisón, 1991), ciertamente poco citado, y que entiendo es clave en la vida y la obra de Carmelo. El libro ha sido analizado, resumido y tratado, en cuanto tal, de manera excelente por Eloy Gómez Pellón (2012), por lo que no es mi intención entrar en su contenido, sino ponerlo en relación con la mirada hermenéutica de su autor. Aunque los antropólogos no han visto en este trabajo mucho potencial (quitando algunas referencias menores como la de Talego (2009), a la contra de los historiadores modernistas que lo han leído con un cierto grado de profusión, haciendo de él un lugar común a la hora de entender el complejo mecanismo de los sistemas rituales de la corte de los Austrias (Casal, 2014; Feros, 2002; Negredo, 2002; Nieto, 1993). Un libro que presentaba el Discurso de entrada en la Real Academia de Ciencias Morales y Políticas y al que Carmelo tenía un especial cariño; y donde volcó mucho de su pensamiento, pero también una clara intención de generar un diálogo metodológico y una crítica epistémica, desde un tiempo presente a otro tiempo, donde él entendía ocurrió algo que significó la base de lo que posteriormente sería la España real y Real, la España que había interpretado en sus trabajos en Oxford, en Galicia y en su nueva mirada a la hermenéutica (gadameriana) que daría lugar a lo que él entendía como un horizonte interpretativo, una manera de relacionarse con objetos complejos que requerían de semánticas enredadas en niveles histórico-interpretativos.

Yo guardo con extremo cariño el libro dedicado por Carmelo y, aún hoy tengo dentro la invitación a la recepción, a la que no pude al final acudir porque me marchaba a mi particular periplo por América unos días antes y al que tanto me animara él con sus consejos. Veo con cercanía la dedicatoria, en aquella letra de rasgos casi colegiales, limpia y ordenada donde destacaba ese arrastre que hacía de la letra $a$ y donde era obvio que había tenido tiempo, horas de escritura y reflexión sobre la caligrafía y cómo se modela como un rasgo personal e intransferible, y la veo cercana porque Carmelo siempre se mostró en sus detalles, en sus maneras de mirar y hablar como un hombre hecho en una tradición propia. De la misma manera, aunque no sé los detalles, la publicación en la Colección Austral 
no es un dato baladí, una colección de libros clásicos, "populares» y donde desde Ortega y Gasset se han publicado todos los grandes clásicos de la lengua castellana y una gran apuesta, desde los años 50 del siglo XX, por llevar conocimiento a los hogares españoles y latinoamericanos. Carmelo, además, se ponía con este texto en un sentido pleno a un lado de su compromiso con la editorial Akal, con la que había editado prácticamente todos sus textos clásicos, mostrando un sentido de autonomía y plenitud muy encomiable para un intelectual que entraba en una Real Academia, templo del saber más canónico.

Dos cosas antes de empezar. La obra de Carmelo no es fácil, no solo esta que ahora nos ocupa, fundamentalmente porque a su búsqueda de una terminología precisa y concreta se añade una disposición a hacer afirmaciones positivas constantemente. Es importante reconocer que Carmelo no quiere discutir ni con los historiadores ni, mucho menos, con los hispanistas (Thompson, 1981; 1993), sino más bien primero establecerse dentro del marco de la antropología política, pero también retomar en un tema aparentemente lejano y tratarlo dentro de las categorías propias de la disciplina: el ritual, los símbolos y las representaciones. Pero también su fuerte convicción de la diversidad, y será desde aquí desde donde el discurso se contendrá en lo más central e importante de la antropología contemporánea. La pregunta que se hace Carmelo es aparentemente sencilla, incluso podríamos decir que ingenua: ¿Qué es un rey? ¿Es solo una imagen, un discurso o detrás hay un ser humano, con sus grandezas y miserias? ¿Y cómo se compaginan ambos mundos, el de la realeza/divina y el del hombre real? ¿Es un juego entre la verdad y lo posible, o hay un lenguaje de significados que nos permite ver la idea de cómo son los sistemas de representación del poder? Lo interesante es que Carmelo constantemente contesta que son símbolos, son maneras de representación, son lingüísticas, son interpretaciones. Obvio que Carmelo reconoce que es mucho más complejo, pero en su sentido antropológico político es así de sencillo: son símbolos en un entramado socio-cultural.

Claro que, como imagen, el Rey, y Carmelo nos lo demuestra de esa manera tan poética y literaria que le caracteriza, hay que construirla, generalizarla (naturalizarla), difundirla y, a lo que a la postre es el significante más importante en un reinado, hay que gestionarla; de ahí el aparato administrativo, la corte en sí misma. En definitiva, nos dirá Carmelo, para contestar a la aparente sencilla pregunta de qué es un Rey: es una imagen gestionada y gestionadora. También hay que recordar que esta pregunta, qué es un Rey, se hace dentro del discurso de entrada en una Real Academia, dentro de un contexto, la monarquía parlamentaria española, donde preguntar qué es un Rey muestra lo valiente de establecer la antropología como centro de la discusión, pero también lo importante que es generar preguntas que, vengan de donde vengan, muestren la complejidad del mundo en el que vivimos. Al utilizar la historia como si de un espejo se tratara nos muestra, a través del pasado, nuestra más profunda verdad. Como haría unos años después, en la Contestación al discurso de Ricardo de Sanmartín en su entrada a la Academia (Lisón, 2010), recuerda que los rituales, con su liturgia repetitiva y barroca, 
no solo están para cumplirse (principio de autoridad), sino para dar significado profundo al contenido histórico social y cultural que mantenemos como seres humanos (principio de voluntad). Preguntarse qué es un Rey es, consecuentemente, urgente e importante; nos muestra a través del lenguaje y de sus posibilidades de interpretación cómo existe una jerarquización de los símbolos frente a los signos, donde existen una contraposición entre las metáforas y las representaciones: el rey no sólo es un símbolo, es ante todo el signo de su tiempo. La monarquía, aquella de los Austrias que él muestra, como esta que ahora nos contextualiza, no es una única unidad, sino más bien un hecho histórico de negociaciones, intereses y voluntades varias.

Obviamente que el libro La imagen del Rey trata un tema clave para la antropología social en general y la política en particular ${ }^{1}$ : la universalidad de las formas monárquicas, en cuanto que una forma de teoría política, y las particularidades reales, que podemos ver de manera ejemplar en los Austrias, son un buen ejemplo de la complejidad de la interpretación, los intereses y las maneras socio-culturales -de hecho, de aquí parte González Alcantud (2013) para su estudio de la monarquía alauita y también Lobato y García (2003)-. Carmelo analiza los significados profundos de un momento de España y sus monarquías donde la política y la religión no se podían diferenciar, pero que tampoco estaban amalgamadas; por decirlo rápido, Carmelo en este ensayo introduce a los territorios gobernados por los Austrias dentro, primero, de una discusión teórica que desde Frazer, a finales del siglo XIX, se había tratado como un tema central de la antropología simbólica: la política y el arte como formas de representación simbólico-social. Segundo, plantea un método, en el interés por discutir con Frazer, Hocart, y con su propio maestro Evans-Pritchard, con el que centrará la mirada sobre las estructuras simbólicas que subyacen tras lo obvio. Y, tercero, toma la palabra histórica para actualizarla. Gracias a la magia operatoria de la hermenéutica gadamediana, con la que discute, se disuelven en pos de llegar a otro punto importante: un escrito profundo, claro y bien documentado que resalta la importancia de la antropología, como una gran generadora de conceptos con los que entender al ser humano desnudo y verdadero como una totalidad, incluso aun cuando estén revestidos de los ropajes de reyes-divinidad.

1. El libro de Carmelo fue editado en 1991. Un año antes, Morán (1990) publicó un libro sobre la imagen del rey Felipe V y el arte. González, Usunáriz y López (1999) editaron un libro sobre la imagen del rey y su transcendencia en las fiestas públicas. Cañeque (2004) utilizó la idea de la imagen real para entender el complejo sistema de representaciones políticas en el México colonial y Carrió-Invernizzi (2008) para la Italia española. Obvio que "la imagen del rey» no sólo es un tema antropológico, sino ante todo de la historia moderna, lo que le da al trabajo de Lisón una mayor importancia y valor si cabe. 


\section{LOS AUSTRIAS, UN OTRO CULTURAL}

El periodo de los Austrias es especialmente rico e interesante: la consolidación del moderno estado mundial, la aparición de las economías basadas en los patrones monetaristas, la expansión europea en forma de colonialismo, las consolidaciones territoriales y los pactos para terminar con las guerras de religión, la construcción de muchas categorías asociadas a la raza y al género, las discusiones sobre la construcción del ser humano y las separaciones entre sociedad civil y religión. Pero el periodo de los Austrias es también a un nivel mucho más local un momento clave: consolida el proyecto hispánico en torno a la idea de la monarquía y establece un mundo, el de la corte que, con sus rituales, sus artes, sus enormes asuntos de política internacional y los equilibrios entre los territorios nacionales ha dejado una clara impronta de la modernidad en su sentido más amplio y ambicioso (Bennassar, 2006; Bermejo, 2005; Ribot, 2006). Obvio que el trabajo de Carmelo ya reconoce estos y otros puntos en el interés sobre la historia de España, pero él lo saca de ahí para llevárselo a un terreno que le es más claro: la figura del Rey y su papel como imagen política, los símbolos regios y su relación con su tiempo, con los constructos temporales que lo sustentan y que lo significan. El rey, como una unidad semántica, y el poder como su práctica cultural.

En consecuencia, la idea de la España Imperial, en la medida que existe algo que interpreta a los hechos, que lo hace además desde una disciplina como la historia, que tiene sus propias preocupaciones y discusiones, no es el interés de la antropología, acaso como dato, en su defecto como hecho cultural que muestra las formas de relación y normalización del pasado y, en su caso, las maneras de establecer nexos con la memoria: pero en cuanto parte del análisis la clave es tomar lo social como un entramado abierto a una interpretación que nos permita entender a esos otros. Los Otros son el eje sobre el que péndula la antropología, y estos Otros son la materia, a veces un tanto oscura y opaca, sobre la que trabaja la idea de diversidad, un elemento clave para entender la idea de cultura. La historia para Carmelo no es sino un espacio donde acudir a ver a los otros, a unos otros que no son diversos por lejanos en el espacio, sino por serlo en el tiempo. De esta manera, aparentemente tan sencilla, rompía él con la idea de exotismo que perseguía a la antropología desde sus inicios. Al acudir a los Austrias, consecuentemente se enfrentaba con un doble otro, o más bien, una dimensión doble de la otredad, por un lado, estaban lejos en el tiempo y lo estaban en cuanto que era la "antítesis" de lo popular, la monarquía era una cultura ajena y diferente de la cultura general.

A diferencia del sentido común a lo Caro Baroja, que afirma que España es un mapa de diferencias, Carmelo cree en la diversidad y en cierta medida estuvo ahí cuando piensa en los gitanos, los chuetas, los gallegos, los vaqueiros o lo maragatos en la década de los 70 del anterior siglo como mosaico de culturas que comparten un territorio. 20 años después el propio Carmelo acude a la historia para romper con este esquema, para preguntar: qué habría más lejano, diverso y 
extraño en España de esos gallegos que estudiaba de manera inequívoca y exagerada, obviamente que la corte imperial de los Austrias, tan lejanos en el tiempo, en sus rituales y formas de pensar que ambas sociedades serían casi irreconocibles entre sí, o como ocurre cuando pensamos en la brujas como categoría socio-cultural más allá de lo histórico-contextual (González Alcantud y Lisón, 2016; Lisón, 1992). No porque se nieguen, como diría un historiador al uso, sino porque el mundo es en toda su extensión diverso, replicará Carmelo. Comprender la obra de Carmelo no es fácil, tuvo algunos giros tajantes que hacían que fuera cada vez más radicalizándose hacia la hermenéutica (Couceiro, 2012; Sanmartín, 2012; 2020; Traimond, 2012), de lo que no pocos reconocen una lectura de la obra de lo que el filósofo alemán Hans-Georg Gadamer (1988: 372) llamó historia efectual: "La conciencia histórico-efectual es un momento de la realización de la comprensión, y que opera ya en la obtención de la pregunta correcta». Carmelo ya había planteado mucho de todo esto en su mirada hermenéutica (Lisón, 1983)², donde bosqueja que todo lo social es un hecho cultural en un entramado histórico y de voluntades-tradiciones mantenidas en la estructura simbólica-lingüística y en el proceso ritual. Para Carmelo la hermenéutica es, a través de Gadamer, ante todo un método para poder interpretar, pero también una finalidad de descripción.

En el libro que nos ocupa, un pequeño ensayo que trata de las paradojas históricas que se dan desde la construcción de ese entramado complejo de territorios e identidades que es España, donde los reyes siendo tanto de España y sus reinos como de otros lugares por igual: siendo reyes de España no son reyes españoles hasta bien entrado el siglo XVII. Así como la mirada cotidiana en la vida de la Corte, con sus problemas para poder gobernar sin perder todo aquello que les envestía, hasta, definitivamente, el minucioso análisis a la imagen del Rey, como un lugar no sólo de representación sino de construcción de un entramado simbólico y ritual muy cercano a las formas artísticas que en su mismo tiempo producían pintores, arquitectos y literarios varios. Para llegar hasta ahí se toman los escritos de la época como si fueran informantes sobre el terreno y trata de desgranar las diferentes unidades lingüísticas, textuales y de conformación del ritual en su propio proceso de pensamiento. Carmelo propone una mirada hermenéutica donde lo que expresa rompe las fronteras de los saberes concretos, del tiempo y los conceptos dados (Lisón, 1996).

En este mi trabajo, el de cruzar la mirada de dos grandes pensadores, no hago sino acercarme a la obra de Carmelo desde su admirado Gadamer, a la vez que intentar entender el complejo pensamiento de Carmelo en función de ese

2. Carmelo, desde los primeros años 80 del siglo pasado y hasta el día que dejó de dar clases de doctorado en la UCM a principios de los 90, recomendaba a sus alumnos de postgrado el hacer un trabajo donde se entrecruzara una breve reflexión del campo y el libro Verdad y Método. Introductor de la hermenéutica en la antropología española fue fiel a este planteamiento y sus valores hasta más allá de cualquier academia o planteamiento universitario. 
rizoma complejo de realidades lingüístico-simbólicas que preconizaba su forma de construcción intelectual. A diferencia de Carmelo, preocupado por entender la diversidad en su propia construcción socio-cultural, el principal interés de Gadamer es liberar a los conceptos de juego y de arte de la carga subjetiva que presenta en Kant y en Schiller (Jiménez, 1983; Roldán, 2012), como en otro sentido en Walter Benjamin (Núñez García, 2005); lo que más tarde, para Carmelo, significará entender el campo de los valores como elemento básico de la idea de culturavivida. Así pues, para Gadamer el juego posee una esencia propia independiente de la conciencia de los que juegan, al igual que la obra de arte posee una esencia propia independientemente de la subjetividad de los que la contemplan, el sujeto es más bien el juego que el jugador, es «el primado del juego frente a la conciencia del jugador» (Gadamer, 1988: 147). La valiosa conclusión gadameriana es que hacemos mal en habernos acostumbrado a remitir tanto juego como arte a la conciencia subjetiva. ¿Por qué el arte es juego, según Gadamer? ¿Por qué para Carmelo el ritual es una representación? Porque el juego es "representación» y el arte también, porque el juego como el arte es un mundo cerrado en sí mismo que es experimentado por el jugador como una realidad que le supera, ya que el mundo del juego no se mide con ninguna otra cosa que esté fuera de él y, de todas formas, desde él habla una verdad superior. Así también para Carmelo el arte, en la medida que se funda en semas, es más verdadero que la realidad: la realidad es lo no transformado, mientras que el arte es la superación de esta realidad en su verdad, a su vez el ritual político es una hiper-realidad.

No obstante, hay una pequeña diferencia entre ritual y arte: el arte es siempre representación "para alguien", el ritual no acostumbra a representar para nadie porque no tiene carácter de exhibición, de modo que mientras que es autorepresentativo, el arte es heterónomo-representativo, representación siempre para alguien. No obstante, dicho carácter de exhibición del arte puede ponerse en cuestión por filósofos de la talla de Benjamín en pro de su valor sagrado. El ritual, planteará Carmelo, alcanza su perfección de ser arte mediante su transformación en una construcción, es decir, transformación hacia lo verdadero y construcción de otro mundo, de manera que quien experimente este fenómeno de transformación en una construcción se habrá modificado a sí mismo para toda su vida (Lisón, 2012); de la misma manera que el arte es una experiencia que modifica a quien lo experimenta, así también la esencia del juego modifica a quien lo experimenta y queda reflejado en el comportamiento lúdico, de manera que si «todo jugar es un ser jugado", todo experimentar arte es un experimentarse. ¿Por qué el arte tiene ese potencial modificador? Porque en el arte hay un auténtico conocimiento esencial debido a que la representación no es como tradicionalmente se piensa (repetir copiando) sino que en la representación del arte tiene cabida la verdad de las cosas, lo cual el hombre reconoce y conoce, y en la medida que reconoce y conoce en ella algo, en este algo se reconoce también a sí mismo (Benjamin, 1970; 1982). El goce que produce la representación es el goce del conocimiento, las imágenes representativas del arte captan y muestran la esencia de las cosas 
del mundo y gracias a ello el arte nos ofrece imágenes «reales» del pasado. Si el conocimiento de la verdad es el conocimiento de las esencias, entonces el arte accede a la verdad. En definitiva, la verdadera experiencia de una obra de arte es "conocer", todo lo demás es irrelevante.

El ser de la representación es más que el ser de lo representado. Carmelo nos propone que mirar la imagen de los Austrias es mirar una estructura político-social holística y compleja, significativa y real. De la misma manera, Gadamer pone el ejemplo de un cuadro de Velázquez, "La rendición de Breda», en el cual lo representado es una rendición militar. Sin embargo, la representación adquiere el carácter casi de un sacramento militar, de modo que se puede afirmar que el arte es el proceso de ser de la representación. Bien es verdad que pueden existir variaciones en la representación de la obra, pero dichas variaciones no son libres y arbitrarias, sino «vinculantes»: «es seguro que nadie atribuirá a la interpretación de una obra musical o de un drama la libertad de tomar el texto fijado como ocasión para la creación de unos efectos cualesquiera; y a la inversa, todos consideraríamos que se entiende mal la verdadera tarea de la interpretación si se acepta la canonización de una determinada interpretación" (Gadamer, 1988: 164). Por eso Carmelo aprovecha para afirmar que el baremo de la representación correcta es móvil y relativo, incluso que la idea de una única forma adecuada tiene algo de absurdo cara a la finitud de nuestra existencia histórica, por lo que vemos la interpretación no funciona como un hecho, sino como un ideal regulador.

\section{UNA HERMENÉUTICA ENTRE EL RITUAL Y EL JUEGO}

Uno de los rasgos más importantes del Ritual es que éste consiste en liberarse de la tensión que domina el comportamiento cuando se orienta hacia fines u objetivos. Gadamer lo pensaba cuando lo aplica sobre el juego, que es la pura realización de movimiento sin objetivo, ni intención y que aparece entonces como el auto-movimiento que no tiende a una meta, sino al movimiento en cuanto movimiento, que indica por así decirlo, un fenómeno de exceso, de la auto-representación del ser viviente (Gadamer, 1991: 67). De manera parecida lo entiende Carmelo cuando piensa en el ritual de los Austrias, en sus formas de representación/acción donde, pese a estar libre de fines, este ritual hace uso de la racionalidad que sería la obediencia a las reglas que el propio protocolo Real plantea (Lisón, 1992). De ello se deriva una pregunta a reflexionar: el arte, como el ritual, ¿no tiene objetivos ni intenciones? Para Carmelo la única intención que hemos de admitir en el arte es que nos ayude a situarnos mejor en el mundo, por lo tanto, es una finalidad evidentemente práctica.

Entender el arte como juego tiene especial significado en la teoría del arte contemporáneo, ya que uno de los impulsos principales de éste es el deseo de anular la distancia que media entre el público y la obra, de manera que se ha concebido al espectador como un co-jugador (García, 2006). El ritual es un hacer 
comunicativo, un jugar-con, el juego no conoce la distancia entre el que juega y el que mira el juego, pongamos por ejemplo cuando Carmelo en su libro nos plantea ver el entramado simbólico-comunicativo del Emperador (Carlos V) en donde los espectadores son también el público de un algo que se vive, en su propio carácter barroco, como algo glorioso, un momento único en la vida de los que participan, borrándose las fronteras entre actores y espectadores, de hecho los movimientos del Emperador/Rey eran seguidos con un bullicio, vivas, aplausos y música que no son otra cosa que "participatio", es decir, ese público es algo más que meros observadores, son co-rituales porque participan del espectáculo en una relación simbiótica y compleja. Lo interesante es que Carmelo, en esta idea de leer desde Gadamer, nos propone algo parecido, una cosa así es lo que ocurre con el arte, y especialmente con el arte contemporáneo debido a su vertiente más experimental. Es un error creer que la implicación del espectador como co-jugador quiere decir que la obra ya no existe, como conciben muchos artistas y teóricos del arte, la unidad de la obra y su identidad hermenéutica no conllevan su clausura frente al que se dirige a ella, sino la interpelación a todo aquel que la contemple. Vemos, así, como Carmelo defiende que sólo habrá una experiencia artística real para aquel que juega con y en la obra. La identidad de la obra consiste precisamente en que hay algo que entender como aquello que nos cuenta la misma, es éste un desafío que sale de la obra y que espera ser correspondido, «exige una respuesta que sólo puede dar quien haya aceptado el desafío, y esta respuesta tiene que ser la suya propia, la que él mismo produce activamente» (Gadamer, 1991: 73).

Para Carmelo consecuentemente el ritual barroco es algo que tiene que ver, directamente con el arte y desde ahí quiere entresacar su significado, parafraseando partes de su libro: las entradas reales eran toda una obra de arte. Se programaba con meses de antelación; autoridades, clero, burguesía, burocracia y masa contribuían todos a preparar un espectáculo gigante político-estético-religioso que requería del concurso del poeta y del carpintero, del criado y del amo, del tamborilero y del coreógrafo. Montaban arcos triunfales, teatro callejero, fuentes, escenas bíblicas, alegorías de virtudes y vicios, pasos de costumbrismo local, danzas de salvajes, atracciones acuáticas y luminarias en lugares elegidos, estableciendo así un múltiple diálogo activo entre el rey y la comunidad. Levantaban «miraderos» a lo largo del recorrido para poder saborear el espectáculo, se apiñaban en balcones, ventanas, tejados y terrazas para ver al héroe que lucía sus mejores ropas e insignias. Más de 1.200 caballeros con hachones recorrieron las calles madrileñas en la entrada de Mariana de Neoburgo. Felipe II hizo su entrada en Sevilla por el río, para lograr mayor impacto y esplendor. Le reciben «tres mil menestrales bien lucidos y armados y quinientos de Triana». De este modo, el espectador forma parte del juego del arte ya que toda obra deja al que la recibe un espacio de juego que éste tiene que rellenar. De esta mirada sale el mejor Carmelo y el más atento Gadamer (1991: 73): «la identidad de la obra se haya enlazada con la variación y la diferencia». Gadamer explica esto con un ejemplo de una descripción de una escalera que realiza Dostoievski en su libro "Los hermanos Karamazov»: el narrador 
describe la escalera de un modo en el que se capta perfectamente cómo es ésta, sin embargo, sabemos que nadie ve la escalera de la misma forma, no hay dos visiones que coincidan totalmente a pesar de que esté perfectamente descrita, no obstante, todo aquel que vea la escalera estará convencido de verla tal como es. Para Carmelo, el ritual barroco es el momento es que hay una participación que no es fácil describir porque se ha hecho para vivir.

Para Gadamer, como en el ritual barroco que describe Carmelo, en las artes plásticas ocurre algo semejante, ya que «un cuadro se lee, igual que se lee un texto escrito, se empieza a descifrar un cuadro de la misma manera que un texto, la pintura cubista no fue la primera en plantear esta tarea, si bien lo hizo con una drástica radicalidad» (Gadamer, 1991: 35), de la misma manera que el imaginario de los Austrias está influido por la multiplicad de descomposiciones que hacen los actores/espectadores, no sólo es en el caso de Picasso que leemos un cuadro, es como el ritual Real se hace múltiple y complejo. Con esto vemos en Carmelo una gran lección: siempre hay un trabajo de reflexión, de lectura y análisis, lo mismo si nos ocupamos de formas simbólico culturales tradicionales, de rituales reales en el siglo XVII, de una creación política o si recibimos el desafío del arte contemporáneo; es decir, por experiencia propia, todos sabemos que visitar un museo, beber una copa de vino o escuchar un concierto son tareas de intensísima actividad simbólico-cultural y después de ellas no se sale con el mismo sentimiento vital con el que se entró: si se ha tenido la experiencia del arte el mundo se habrá vuelto más leve y luminoso (parafraseando a Gadamer, 1991: 73).

Carmelo rompe la tradicional yuxtaposición entre las formas culturales del pasado, con el cual se enfrenta la descripción, y la sociedad actual, en el cual hay que participar, porque para él ambos mundos han de ser leídos y leer significa ejecutar el movimiento hermenéutico que gobierna la expectativa de sentido del todo, de modo que la identidad de la obra humana no se hace efectiva por su clausura frente al espectador, sino que se hace efectiva al hacernos cargo de la construcción de la misma como tarea. Carmelo, una vez más vuelve a leer a Gadamer (1991: 79) porque: «precisamente es la no-distinción entre el modo particular en que una obra se interpreta y la identidad misma que hay detrás de la obra lo que constituye la experiencia artística». Y no sólo es esta no-distinción, sino que también es lo contrario a realizar distinciones secundarias como la diferenciación entre la actuación de los actores en concreto y la ritualidad simbólico-cultural, dejando de lado al simple «degustador de estética» (Gadamer, 1996): aquel que va a un ritual porque es lo que se debe y no porque se representa por algo concreto, lo que afirmativamente no le va a proporcionar ninguna experiencia. Mirada realmente significativa que denuncia tanto al fariseo, como al pensador de los hechos ajenos y que no ven su trabajo, el propio o el ajeno, como una verdadera experiencia de vida. Porque Carmelo había entendido en sus estudios en Galicia esta poderosa enseñanza que aplica con el ritual barroco de los Austrias: la experiencia de un hecho cultural se culmina cuando de lo que uno se asombra es justo de la 
discreción de los actores, éstos que no se exhiben a sí mismos, sino que evocan constantemente el ritual.

Y desde aquí podemos saltar a otro hecho que es uno de los verdaderos problemas para Carmelo, y que ya había sido algo que había tratado en su trabajo en su tesis doctoral en Oxford: los hechos culturales pueden sustraerse a su tiempo, pero no a su temporalidad, ¿qué clase de temporalidad es ésta, acaso una historial efectual? Es un enigma de orden semántico-simbólico y que se manifiesta en el fenómeno de la fiesta. Ella es la que hace que en el ritual concreto el hombre que observamos pueda acceder al tiempo redimido. Es decir, sólo a través del arte el hombre puede alcanzar momentos de vida auténtica dentro de un tiempo finito de vida humana. ¿Qué quiere decir celebrar una fiesta?, ¿tiene tan sólo el significado negativo de no-trabajar? Evidentemente el trabajo nos separa y divide; por el contrario, en la fiesta todo está congregado; la fiesta es comunidad y la celebración es una actividad intencional, dado que hay un designio que une a todos y les impide desintegrarse en vivencias individuales. ¿Por qué es tan importante la fiesta para Carmelo? Porque el propio orden del tiempo se origina en la repetición de las fiestas. Para él, y en esto parece planear sobre todas las ideas de Gadamer, hay dos clases de experiencia del tiempo: el tiempo "vacío" que hay que tener para llenarlo con algo, cuyos extremos son el aburrimiento (se llena con la nada) y el trajín, aquí entonces el tiempo se experimenta como algo que se tiene que pasar o que ha pasado.

Por lo tanto, el tiempo no se experimenta como tiempo. Pero, por otro lado, existe otra experiencia del tiempo que es la experiencia de la fiesta, la cual llena al tiempo y lo convierte en un tiempo lleno. Esta segunda experiencia del tiempo es afín al ritual y al arte, por lo que ambos poseen un tiempo propio, parafraseando de nuevo a Gadamer (2013), llegamos a la conclusión de que la obra de arte (como el ritual) no está determinada por la duración calculable de su extensión en el tiempo, sino por su propia estructura temporal que todo hecho humano significativo posee e impone. Carmelo, desde aquí y leyendo las «imágenes del rey», conserva que lo único que nosotros podemos hacer es aprender a demorarnos en ella, en su imagen, porque la esencia de la experiencia temporal del ritual y el arte barroco consiste en aprender a demorarse, porque lo que intentamos en nuestra relación con la cultura es retener lo fugitivo en una nueva permanencia propia. De la misma manera que la imagen del rey deja claro que ni la raza, ni el credo religioso, ni el pequeño reino de este mundo, ni el espacio, ni el tiempo afectan a la naturaleza de la legítima y deiforme realeza.

\section{REYES CONTRA MONARQUÍAS, LA HISTORIA ES UN TEXTO}

El ser de la fiesta tampoco debe entenderse como la subjetividad del que lo festeja. La fiesta posee una esencia independiente del que la celebra. Esta esencia es cambiante, pero es una, la fiesta es tal que cada vez es otra, aunque se 
la celebre exactamente igual, ya que la fiesta es un ente que sólo es en cuanto que continuamente es otro. Al ser de la obra de arte y de la fiesta le conviene el carácter de simultaneidad, este concepto procede de Kierkegaard y significaba que cada vez que en el mundo se daba un acto de fe volvía a ocurrir simultáneamente el nacimiento de Cristo que aconteció hace más de 2000 años, de modo que la salvación del hombre de los cristianos acontece en cada instante siendo una superación del tiempo lineal y físico. Carmelo se sirve de este concepto de simultaneidad, pero retocándolo: es el ritual y los sistemas semánticos, y no la fe, lo que hace al hombre participar en la eternidad. Según Aristóteles, la tragedia producía un efecto de catarsis o purificación en el espectador. Carmelo extiende el efecto de lo trágico a todo el entramado simbólico-ritual, ya que piensa que el encuentro con los hechos, del presente o del pasado, son un encuentro del espectador consigo mismo (Lisón, 2009). Esto ocurre porque el lenguaje de los rituales barrocos tiene su alcance todavía. Es más, su análisis de las formas reales es todo un ejercicio de antropología comparativa y de cultura política entendible en todo tiempo y espacio. Además, ante el ritual barroco el espectador no se comporta con la distancia con que la conciencia estética disfruta del arte, sino al modo de la comunión del asistir; más aún, hay una continuidad de sentido que reúne los hechos culturales concretos, con el mundo de la existencia. Así lo entiende Carmelo al hablar de la dignitas del trono, esto es, del rey, cualidad que singulariza a una única persona y es inseparable e inmanente a la realeza. Este intensivum, tan antiguo como la realeza, sólo puede describirse connotativamente, como una guidditas regia o maiestas mística o valor metafísico, supraindividual y perpetuo, con existencia independiente, inmortal, aunque muera el rey y, en cuanto ente de razón, eterna. Concretamente y a un segundo nivel lógico, este sema distintivo viene injertado en la singularidad del officium real, esto es, en la soberanía que sólo al rey pertenece pero que ennoblece, por participación, al reino entero.

Todo lo que observamos del mundo no es un mundo de delirio o encantamiento, sino que sigue siendo el propio mundo, el propio mundo que uno se apropia ahora de una manera más auténtica al reconocerse más profundamente en él (De Man, 1998). Tanto la lectura, como la traducción y como la interpretación tienen que superar una distancia: para la lectura es la distancia texto/palabra, pues en un diálogo es más difícil que se den los fondos de vacío ya que se formulan preguntas y aclaraciones directas de los interlocutores; sin embargo en la lectura y la traducción es una distancia entre lenguas porque el autor al escribir en su lengua materna se distancia de todos los que hablan otras lenguas; para la interpretación es una distancia entre el lenguaje de la obra de arte (bien sea pictórico, escultórico, arquitectónico, musical, teatral, literario, etcétera) y el lenguaje humano de destino (Vallejo, 2004: 465-486). Una vez reconocidas todas estas cosas podemos preguntarnos, ¿cómo salvan la lectura, la traducción y la interpretación sus distancias? Gracias a la tesis ontológica de la hermenéutica gadameriana de que «el arte salva todas las distancias» (Gadamer, 1998: 89). Y así Carmelo entiende que el intérprete esté distanciado temporalmente de la obra, no obstante, puede 
comunicarse con ella gracias al arte; también en una obra espacial (un cuadro o una catedral cuyo lenguaje no es el literario) el intérprete puede traducir la imagen (la propia materialidad de la obra de arte) en palabras.

Así para entender al rey barroco, a los Austrias en su conjunto (Checa y Fernández-González, 2016; Salazar, 2017) hay que enfrentarse con su propia semántica en la medida que actúa tanto de lector, como de intérprete. Se pregunta Carmelo, ¿cuál era al principio el status ontológico de la realeza en la Península? ¿Reproducía o no esos atributos frazerianos? ¿De qué metáforas, paralelismos y emblemas se servían para marcar y distinguir la persona del rey? Según el concepto hispano-godo de la realeza, el poder, que emanaba de Dios, estaba depositado en la persona sagrada del rey, el cual tenía obligación, a lo Hocart y Frazer, de procurar el bien público utilitas publica. Esta doctrina teocéntrica y de deificación, seguimos leyendo a Carmelo en su libro, del monarca adquirió una concreción específica y solemne en los rituales de unción y coronación que hacían del príncipe un rex-sacerdos, un semisacerdote. Estas regias ceremonias litúrgicas, altamente simbólico-políticas, eran la encarnación de una idea: la asociación de la realeza con la divinidad (Chamorro, 2013). Pero el ritual hace algo más. Y Carmelo reconoce que el ritual es puramente un tiempo significativo, por lo que, si el rey es legalmente rey antes de la unción y coronación, como efectivamente lo es, ¿para qué dramatizar solemnemente, con la mayor pompa eclesiástica posible en el espacio más sagrado y a los gritos de la plebe encantada que claman a su Rey? El ritual tiene un aspecto misterioso y otro numinoso y sólo de él emana un valor simbólico que conecta al ritualizado de modos diferentes con la divinidad. La periodicidad cíclica de estas ceremonias en las diferentes catedrales no sólo servía para potenciar el status e investir a la realeza de un halo extra; le confería a la vez y, además, una dimensión de permanencia e intemporalidad y alzaba a la realeza al orden inalterable de las cosas. La monarquía así visualizada era inmune al cambio; el conjunto integrado de creencias, ideas y valores que la aureolaba sintetizaba conceptos e imágenes referentes a los principios inalterables de la existencia, al orden moral perenne y supremo y, por tanto, una vez más, sagrado, como su tema temporal determinante. Regnum y sacerdotium tienen, pues, un coeficiente de atributos comunes.

Para Carmelo el arte, el ritual y las estructuras simbólico-culturales surgen del pasado y aparecen en el presente, son intemporales y eternos, de modo que la interpretación de estos hechos es la manera que le cabe al ser humano de participar en la eternidad: "la verdadera vida está en el arte» tanto para Gadamer, para Carmelo, como para Hegel (Vattimo, 2010). Y así volvemos al tema de la traducción, si Gadamer reflexiona sobre los grados de intraducibilidad afirmando que lo más traducible es la novela y lo menos la poesía lírica, por lo tanto "no es accidental que la acuñación del concepto de literatura universal fuese simultáneo a la extensión del arte de la novela» (Gadamer, 1998: 90), siendo la extensión de la cultura de la lectura lo que ha convertido a la novela en la literatura ya que requiere una traducción universal porque es cosa de la cultura de la lectura. En la poesía la 
traducción es más difícil porque además de ser leída y entendida ha de ser oída y las configuraciones fónicas de las diferentes lenguas son intraducibles, de manera que el traductor no puede mostrar totalmente el tono del poema original en su traducción, con lo que tiene que conformarse con llevar a cabo una adaptación. En efecto, según Gadamer (1997), los traductores son «más que intérpretes» porque salvan la distancia existente entre dos lenguas y dos textos (original y traducción) dejando así para nuestra lectura un puente transitable en ambos sentidos.

Carmelo traerá todo esto a colación cuando se plantea la universalidad de los semas culturales, ya que, inducidos por el ejercicio de la palabra, y su libro de la imagen del Rey es un larguísimo excurso de gentes de los siglos XVI y XVII, nos viene a plantear en cuanto que imágenes de la autoridad y el poder absoluto ¿Se veían "divinos» los monarcas austríacos? La respuesta, dirá Carmelo, no es nada fácil dada la politropía del término y la diferente idiosincrasia de cada uno de ellos, pero no cabe duda, al menos, de que todos se consideraban en su realeza corno personas sagradas y corno vicarios de Dios en la tierra. Y algo más a juzgar por las regalías que tan tenazmente defendieron frente a los Papas. Con los Austrias el Estado continuó su proceso de sacralización que ya había comenzado con el Rey Católico; sus más dinámicos representantes hicieron valer sus roles de rex-sacerdos y de vicedioses para incrementar considerablemente sus funciones regias en el ámbito eclesiástico. Entonces, desde un ejercicio hermenéutico, ¿cuál es la idea de texto eminente? No se refiere a que el hecho cultural satisfaga una necesidad coetánea de información, sino que se refiere a que la interpretación de la obra literaria, incluida la que se genera por el propio crítico, analista o exegeta se erige en una pretensión de validez independientemente de su contenido. Además de su inagotabilidad, pues como obra de arte que es, el texto eminentemente exige ser releído, aunque haya sido anteriormente comprendido. Los semas, ya sean los de los perfiles morales de la cultura gallega o los centrales de la imagen real nunca pueden ser agotados; transformándolos en conceptos», porque estamos ligados a las leyes de la temporalidad y la lectura, que como nosotros también son temporales.

\section{EL REY COMO UNA INTERPRETACIÓN CULTURAL}

Dice Carmelo en su propio texto sobre la imagen del Rey, que el resultado de esa antropológica-investigación se concreta en una configuración de la monarquía/realeza austríaca conformada por una serie de valencias ónticas o determinaciones o modos de existencia que han hecho posible su reconocimiento y apropiación. Con sus vidas y actividad, con sus palabras y hechos han representado y manifestado, en emic y en etic, explícita e inconscientemente, la naturaleza de la monarquía y la esencia de la realeza (res contra rey). No pretende haber pasado de un sondeo inicial del tema en este ensayo, pero puede hacerse la siguiente pregunta: ¿tiene algo de específico y único, incomparable e inconmensurable, en 
su constitución esencial, la monarquía/realeza de los Austrias? O por el contrario, ¿forma parte de una configuración mítica o área cultural más extensa?

Son preguntas que están en la raíz de la antropología, y que la hermenéutica de alguna manera la universaliza en esta otra: ¿cuál es la idea de verdad en una obra cultural? Desde ahí parte Carmelo ya que puede ser que los Austrias no puedan ser entendidos, o que se hayan configurado en una estructura mítica o que pertenecen, con sus ideas y maneras, a algo más complejo y extenso. No es la verdad científica, ni la verdad como adaequatio intellectus ad rem, sino que es una verdad ontológica: el lenguaje como lugar en el que el hombre se descubre a sí mismo y al mundo. Además, la interpretación cultural posee una «suerte de veracidad» que corresponde a su esencia, ya que en la cultura simbólica el lenguaje es más diciente porque dice más de lo que puede decir el decir, de nuevo parafraseando al Gadamer de Verdad y Método. De hecho, hará que todos los pensadores actuales, tanto hermeneutas como deconstructivistas, entenderán que es fundamental la conversión del lenguaje en objeto de su auto-comprensión filosófica, todo lo cual ha sido así desde Heidegger (Missaggia, 2012; Palmer, 2002); antes el lenguaje había quedado siempre en el marco de la "filosofía de la identidad" teniendo su cenit en el estructuralismo, que mostraba cómo el código es capaz de apresar todos los contenidos de sentido del mundo. Ahora se piensa el lenguaje como una distancia entre pensamiento y realidad y si existe algo de lo que se huye desde Hegel es del subjetivismo moderno: de la intencionalidad de la conciencia y de las tres identidades dobles (sujeto-objeto, pensamiento-ser, naturaleza-espíritu). Debido a esta gran concordancia Carmelo justifica el seguirse ocupando de la construcción cultural como una sumatoria: no hay sinsentido en ningún texto, entonces sólo podemos buscar los sentidos.

La gran diferencia de la hermenéutica con el construccionismo, tal cual lo entiende Carmelo desde su ruptura con las ideas de la identidad como un único valor (Lisón, 1986), es que ésta no busca una experiencia originaria de sentido, ni una meta a la que llegar (la totalidad de significado de los elementos culturales, de la que el símbolo es un reflejo imperfecto) por lo tanto el pensamiento de-constructor puede permitirse el lujo de diferir eternamente sin ninguna exigencia de dirigir sus huellas hacia ningún sitio, y menos hacia el camino recto. Sin embargo, Carmelo, siguiendo a Gadamer, retoma la tarea de descubrir un lugar originario de apertura al mundo que no sea metafísico y para ello regresa, en este caso, a la época de los Austrias que es pre-metafísica y afirma que el diálogo es un lugar primigenio de constitución del significado, donde podemos rescatar el sentido hombre-mundo. Su propuesta, consiguientemente con este libro sobre unos reyes lejanos y misteriosos no es solo generar un conocimiento cultural, es darnos una idea para cualquier otro planteamiento: existen unidades originarias de sentido a la que podemos volver, que no son metafísicas y pertenecen a los hechos del hombre en cuanto que totalidad semántico-cultural.

Además, Carmelo incide en la distancia a la que se enfrentan tanto lectura, como traducción, como interpretación e incluso el lenguaje, no obstante, aporta 
una posibilidad de superación de dicha distancia, ella es el límite simbolico-cultural, el arte, el ritual, el discurso, lo eterno de la producción humana. Aunque los reyes austríacos controlaban la actividad política de la monarquía y siendo jefes de estado y de gobierno, estos eran señores seculares y temporales. Carmelo realza en su ensayo algo esencial: la dimensión Mitra, su actividad simbólico-ritual, el poder místico y esencia deífica de la realeza. Pues bien, a la vista del cuadro podemos inferir que, aunque en diverso grado y medida, con accidentes locotemporales y circunstancias únicas barrocas, la bipartición que dramatizan los Austrias no es en modo alguno específica o privativa de ellos, sino que, por el contrario, actúan en un escenario cultural desde hace tres milenios, desarrollando en esencia el mismo argumento que los otros pueblos indoeuropeos, todos los cuales exhiben idéntica clasificación elemental y complementaria de poderes en tensión. Esta constatación de filiación y pertenencia a una extensa y profunda área cultural, con ser importante y reveladora, presenta un reto intrigante a la reflexión imaginativa del antropólogo. Se pregunta Carmelo: "iquedan por esta incardinación cultural, explicadas así la monarquía y la realeza?», y termina por contestar, en modo alguno, ya que se debe seguir inquiriendo y buscando conexiones más primarias y elementales, principios todavía más universales y englobantes que incluyan, en este caso concreto, a la realeza, o más exactamente preparar el tránsito de la realeza de los Austrias a La Realeza, esto es, a una concepción metafísica que la encarta en otra área de pensamiento e imaginación de mayor distribución. En efecto, Carmelo piensa constantemente en que lo que él hace, en cuanto que antropólogo, es pensar todo en forma de un enorme diálogo, de manera que la virtualidad del diálogo es su capacidad de unirnos en un hallazgo de experiencia de significado, pero para ello hemos de mostrarnos disponibles a aceptar la palabra del otro con nuestras palabras, ahí reside la buena voluntad del diálogo. Cuando el interlocutor está inmerso en el diálogo con el otro, nos propone Carmelo sin dudar, sus palabras se pierden en el otro y desaparecen en el nos-otros. Este ha de ser el modelo hermenéutico para los hechos simbológico-culturales: la buena interpretación desaparece y se diluye en la obra escrita, en el ensayo, quedando presente en ella en forma de ausencia.

\section{REFERENCIAS BIBLIOGRÁFICAS}

Benjamin, W. (1970). La tarea del traductor en La gaya ciencia. Barcelona: Edhasa. Benjamin, W. (1982). Discursos interrumpidos. Madrid: Taurus.

Bennassar, B. (2006). La monarquía española de los Austrias. Conceptos, poderes y expresiones sociales. Salamanca: Universidad de Salamanca.

Bermejo Cabrero, J. L. (2005). Poder político y administración de justicia en la España de los Austrias. Madrid: Ministerio de Justicia.

Cañeque, A. (2004). The King's living image: The culture and politics of viceregal power in Colonial Mexico. Londres, Nueva York: Routledge. 
REYES CONTRA MONARQUÍAS. LA FORMA HERMENÉUTICO-ANTROPOLÓGICA DE CARMELO LISÓN...

Carrió-Invernizzi, D. (2008). El gobierno de las imágenes: ceremonial y mecenazgo en la Italia española de la segunda mitad del siglo XVII. Madrid: Iberoamericana. https:// doi.org/10.31819/9783954872725

Casal Maceiras, O. (2014). La construcción de la imagen pública del poder a través del protocolo y el ceremonial. Referencias históricas. Historia y Comunicación Social, 18, pp. 761-775. https://doi.org/10.5209/rev_HICS.2013.v18.44006

Chamorro Esteban, A. (2013). Ceremonial monárquico y rituales cívicos. Las visitas reales a Barcelona desde el siglo XV hasta el XVII. Barcelona: Universitat de Barcelona.

Checa Cremades, F.; Fernández-González, L. (2016). Festival culture in the world of the Spanish Habsburgs. Londres, Nueva York: Routledge. https://doi.org/10.4324/9781315582245

Couceiro, E. (2012). Estructura social y exégesis simbólico-cultural. El arranque de la antropología hermenéutica de Galicia. Revista Anthropos: Huellas del conocimiento, 235, pp. 151-160.

De Man, P. (1998). La ideología estética. Madrid: Anagrama.

Feros, A. (2002). El Duque de Lerma: realeza y privanza en la España de Felipe III. Madrid: Marcial Pons.

Gadamer, H. G. (1988). Verdad y Método. Salamanca: Sígueme.

Gadamer, H. G. (1991). La actualidad de lo bello. Barcelona: Paidós.

Gadamer, H. G. (1996). Estética y Hermenéutica. Madrid: Tecnos.

Gadamer, H. G. (1997). Mito y razón. Barcelona: Paidós.

Gadamer, H. G. (1998). Arte y verdad de la palabra. Barcelona: Paidós.

Gadamer, H. G. (2013). Hermenéutica, estética e historia. Salamanca: Sígueme.

García Guadarrama, J. L. (2006). El debate Gadamer-Habermas: interpretar o transformar el mundo. Contribuciones desde Coatepec, 10, pp. 11-21.

Gómez Pellón, E. (2012). Sobre contigüidades epistemológicas: antropología e historia. Revista Anthropos: Huellas del conocimiento, 235, pp. 84-96.

González Alcantud, J. A. (2013). Poder y ritual en la monarquía alauita de Marruecos. Granada: Observatorio de Prospectiva Cultural, Universidad de Granada.

González Alcantud, J. A.; Lisón Tolosana, C. (2016). Fragmentos conversados de antropología e historia: La obra de Carmelo Lisón Tolosana. Revista del Centro de Estudios Históricos de Granada y su Reino, 28, pp. 93-102.

González Enciso, A.; Usunáriz Garayoa, J. M.; López, R. J. (eds.). (1999). Imagen del rey, imagen de los reinos: las ceremonias públicas en la España Moderna, 1500-1814. Pamplona: Ediciones Universidad de Navarra.

Jiménez Jiménez, J. (1983). La estética como utopía antropológica: Bloch y Marcuse. Madrid: Tecnos.

Lisón Tolosana, C. (1983). Antropología social y hermenéutica. México, D. F.: FCE.

Lisón Tolosana, C. (1986). Antropología social: reflexiones incidentales. Madrid: CIS, Siglo XXI.

Lisón Tolosana, C. (1991). La imagen del Rey, Monarquía, realeza y poder ritual en la Casa de los Austrias. Madrid: Espasa-Calpe.

Lisón Tolosana, C. (1992). Racionalidad e Inquisición en el siglo de Oro. Anales de la Real Academia de Ciencias Morales y Políticas, 69, pp. 67-83.

Lisón Tolosana, C. (1996). Antropología e Historia: diálogo intergenérico. Revista de Antropología Social, 5, pp. 163-184.

Lisón Tolosana, C. (2009). La emergencia de un nuevo mirar hispano (siglos XV y XVI). Anales de la Real Academia de Ciencias Morales y Políticas, (86), pp. 229-235. 
REYES CONTRA MONARQUÍAS. LA FORMA HERMENÉUTICO-ANTROPOLÓGICA DE CARMELO LISÓN..

Lisón Tolosana, C. Contestación. En R. Sanmartín Arce (2010). Imágenes de la libertad y figuración antropológica en el horizonte de nuestra época. Madrid: Real Academia de Ciencias Morales y Políticas, pp. 85-94.

Lisón Tolosana, C. (2012). Rito, funciones y significado. Música Oral del Sur: Música hispana y ritual, 9, pp. 22-28.

Lobato, M. L., García García, B. J. (2003). La fiesta cortesana en la época de los Austrias. Valladolid: Junta de Castilla-León.

Missaggia, J. (2012). A hermenêutica em Heidegger e Gadamer: algumas confluências e divergências. Griot: Revista de filosofía, 6(2), pp. 1-13. https://doi.org/10.31977/grirfi. v6i2.531

Morán Turina, J. M. (1990). La imagen del rey: Felipe Vy el arte. Madrid: Nerea.

Negredo del Cerro, F. (2002). La palabra de Dios al servicio del Rey. La legitimación de la Casa de Austria en los sermones del siglo XVII. Criticón, 84-85, pp. 295-311.

Nieto Soria, J. M. (1993). Iglesia y génesis del Estado Moderno en Castilla (1369-1480). Madrid: Editorial Complutense.

Núñez García, A. (2005). Walter Benjamín: estética y extrañamiento. En T. Oñate y Zubía; C. García Santos; M. A. Quintana Paz (coords.), Hans-Georg Gadamer: ontología estética $y$ hermenéutica (pp. 581-597). Madrid: Dykinson.

Palmer, R. E. (2002). ¿Qué es la hermenéutica?: Teoría de la interpretación en Schleiermacher, Dilthey, Heidegger y Gadamer. Madrid: Arco.

Ribot, L. (2006). El arte de gobernar. Estudios sobre la España de los Austrias. Madrid: Alianza.

Roldán, A. F. (2012). La reivindicación del prejuicio como precomprensión en la teoría hermenéutica de Gadamer». Enfoques, XIV(1), pp. 19-29.

Salazar Baena, V. (2017). El cuerpo del rey: poder y legitimación en la monarquía hispánica. Fronteras de la Historia, 22(2), pp. 140-168. https://doi.org/10.22380/20274688.109

Sanmartín Arce, R. (2012) Tensiones y armonías culturales del mal. La obra antropológica de Carmelo Lisón Tolosana. Revista Anthropos: Huellas del conocimiento, 235, pp. 109-122.

Sanmartín Arce, R. (2020). Carmelo Lisón Tolosana. Una vocación antropológica. Revista de Antropología Social, 29(2), pp. 103-113.

Talego Vázquez, F. (2009). El poder y la mediación. En B. Roca Martínez (coord.), Anarquismo y antropología. Relaciones e influencias mutuas entre la antropología social y el pensamiento libertario (pp. 95-118). Madrid: La Malatesta.

Thompson, I. A. A. (1981). Guerra y decadencia: gobierno y administración en la España de los Austrias, 1560-1620. Barcelona: Crítica.

Thompson, I. A. A. (1993). Crown and Cortes: Government, Institutions and Representation in Early Modern Castile. Londres, Nueva York: Routledge.

Traimond, B. (2012). La novedad de la obra de Carmelo Lisón Tolosana. Revista Anthropos: Huellas del conocimiento, 235, pp. 57-66.

Vallejo Campos, Á. (2004). El concepto aristotélico de phrónesis y la hermenéutica de Gadamer. En J. Zúñiga García; L. Sáez Rueda; J. A. Pérez Tapias; J. A. Nicolás Marín; J. J. Acero Fernández (coords.), El legado de Gadamer (pp. 465-486). Granada: Universidad de Granada.

Vattimo, G. (2010). Adiós a la verdad. Barcelona: Gedisa. 
